\title{
Algal sulfated carrageenan inhibits proliferation of MDA-MB-231 cells via apoptosis regulatory genes
}

\author{
HOSSAM MURAD ${ }^{1}$, AHMED GHANNAM ${ }^{1}$, MAHMOUD AL-KTAIFANI $^{2}$, \\ ASSEF ABBAS $^{3}$ and MOHAMMAD HAWAT ${ }^{1}$
}

\begin{abstract}
Departments of ${ }^{1}$ Molecular Biology and Biotechnology and ${ }^{2}$ Chemistry, Atomic Energy Commission of Syria, P.O. Box 6091, Damascus; ${ }^{3}$ Faculty of Biological Sciences, Tishreen University, P.O. Box 2237, Lattakia, Syria
\end{abstract}

Received March 18, 2014; Accepted August 5, 2014

DOI: $10.3892 / \mathrm{mmr} .2014 .2915$

\begin{abstract}
Marine algae are prolific sources of sulfated polysaccharides, which may explain the low incidence of certain cancers in countries that traditionally consume marine food. Breast cancer is one of the most common types of non-skin cancer in females. In this study, extracted sulfated carrageenan (ESC), predominantly consisting of t-carrageenan extracted from the red alga Laurencia papillosa, was characterized using Fourier transform infrared spectrometry. The biological effects of the identified extract were investigated and its potential cytotoxic activity was tested against the MDA-MB-231 cancer cell line. The biological biometer of the inhibitory concentration of the polysaccharide-treated MDA-MB-231 cells was determined as $50 \mu \mathrm{M}$. Treatment with $50 \mu \mathrm{M}$ ESC inhibited cell proliferation and promptly induced cell death through nuclear condensation and DNA fragmentation. Characterization of polysaccharide-treated MDA-MB-231 cell death revealed that induction of apoptosis occurred via the activation of the extrinsic apoptotic caspase- 8 gene. The apoptotic signaling pathway was regulated through caspase-3, caspase-9, p53, Bax and Bcl-2 genes. These findings suggest that ESC may serve as a potential therapeutic agent to target breast cancer via prompting apoptosis.
\end{abstract}

\section{Introduction}

Naturally occurring sulfated polysaccharides (SPs) are commonly found in three major groups of marine algae (1). SPs are historically known to exhibit a number of therapeutic and biological effects, including antioxidant (2), anti-proliferative, anti-viral (3), anti-coagulant (4) and anti-tumor/cancer therapy (5-7) abilities. Previous studies have shown that

Correspondence to: Dr Hossam Murad, Department of Molecular Biology and Biotechnology, Atomic Energy Commission of Syria, 17th Nissan Street, P.O. Box 6091, Damascus, Syria

E-mail: ascientific1@aec.org.sy

Key words: red algae, sulfated polysaccharide, breast cancer cell line, apoptosis numerous algal bioactive molecules, SPs included, may be implicated in the low incidences of cancer in countries that traditionally consume high levels of marine food $(8,9)$.

In 2011 , breast cancer was the most frequently diagnosed type of cancer and the leading cause of cancer mortality among females in the United States, accounting for $23 \%$ of the total number of cancer cases and $14 \%$ of cancer-related mortalities (10). Several epidemiological studies have provided evidence that marine algae consumption correlates with lower breast cancer rates in East Asia (11-16). Furthermore, intake of seaweed in the diet has been associated with a low risk of developing breast cancer (11). The potential anti-cancer effects of marine algae are partially attributed to polysaccharide compounds, particularly those which are sulfated, including carrageenans $(17,18)$. Carrageenans are a family of linear SPs which are divided into three categories $(\kappa, \iota$ or $\lambda)$ depending on their degree of sulfonation, solubility and gelling properties (19). A number of studies concerning novel anti-cancer drugs have determined that the modulation of signal-transduction pathways, inhibition of cell proliferation, induction of apoptosis, inhibition of tumor metastasis and inhibition of angiogenesis are all mechanisms which are involved in the control of carcinogenesis $(17,18)$. Therefore, increasing the levels of apoptosis in cancer cells may be an effective method of chemopreventative and chemotherapeutic intervention in numerous types of cancer $(17,18)$.

In the present study, the therapeutic effects of Laurencia papillosa against human breast cancer cells were investigated. The identified extracted sulfated carrageenan (ESC) was evaluated for its effects on the viability and proliferation of MDA-MB-231 human breast cancer cells.

\section{Materials and methods}

Plant material and extract preparation. The red alga L. papillosa was collected from Syrian coastal waters and processed at the Marine Biology Laboratory of Tishreen University (Lattakia, Syria). The collected algal biomass was washed and air-dried at $60^{\circ} \mathrm{C}$ to a constant weight, followed by heating in water $(1.5 \% \mathrm{w} / \mathrm{v})$ for $12 \mathrm{~h}$ with mechanical stirring. The carrageenan extract was dissolved in Milli-Q water (Millipore, Billerica, MA, USA), filtered and immediately mixed with three volumes of ethanol (95\%) (Sigma-Aldrich, St. Louis, 
MO, USA) which caused precipitation of the carrageenan. The extract was collected and oven dried at $50-60^{\circ} \mathrm{C}$ to a constant weight.

Fourier transform infrared (FT-IR) analysis. The IR spectra of the extracted polysaccharide were determined using a Nicolet 6700 FT-IR spectrometer (Thermo Scientific, Waltham, MA, USA). The polysaccharide was ground with spectroscopic-grade potassium bromide $(\mathrm{KBr})$ powder, dispersed in a $\mathrm{KBr}$ disk and pressed into 1-mm pellets for FT-IR measurement in the wave-number range of $600-4,000 \mathrm{~cm}^{-1}$ using 16 scans.

Cell culture. MDA-MB-231 cells [provided by Professor P. Bécuwe from the Cancer Research Unit (EA SIGRETO), Nancy, France] were cultured in RPMI-1640 medium containing 10\% fetal bovine serum (FBS), $50 \mathrm{U} / \mathrm{ml}$ penicillin/streptomycin and $2 \mathrm{mM} \mathrm{L}$-glutamine. The cells were cultured at $37^{\circ} \mathrm{C}$ in $5 \%$ $\mathrm{CO}_{2}$. All materials used in the cell culture were supplied by Gibco-BRL (Carlsbad, CA, USA).

XTT assay. Cells were seeded at a density of $2 \times 10^{3}$ in a 96-well plate. Following a $24-\mathrm{h}$ culture the cells were treated with $\operatorname{ESC}(1,10,50$ or $100 \mu \mathrm{M})$ and incubated for 24,48 or $72 \mathrm{~h}$. Cell viability was measured using an XTT assay kit (Roche, Mannheim, Germany) following the manufacturer's instructions. The number of living cells was quantified by measuring absorbance at a wavelength of $490 \mathrm{~nm}$ using a microplate reader (Multiskan EX Microplate Readers; Thermo Scientific) and the absorption of the controls was set to $100 \%$. A graph of cell viability percentage against ESC concentration was produced from the mean absorbance values, by calculating the percentage growth of the ESC-treated cells compared with the growth of the untreated cells. Treatment with each ESC concentration was conducted in triplicate.

Cell bioimaging. Cells $\left(2 \times 10^{3}\right)$ were seeded into a slide chamber (Nalge Nunc International, Penfield, NY, USA) and cultured for $24 \mathrm{~h}$, followed by treatment with ESCs at the desired concentration. Formaldehyde-fixed cells (4\% formaldehyde) were inspected using a x10 objective lens of an Olympus inverted microscope (Olympus CK2; Olympus Corporation, Tokyo, Japan). Images were then captured using a microscope-branched Olympus DP70 camera (Olympus Corporation).

DAPI staining. Cells $\left(2 \times 10^{5}\right)$ were first cultured in a slide chamber. Following treatment with $50 \mu \mathrm{M}$ ESC, the cells were fixed using $4 \%$ formaldehyde. The cells were washed in phosphate-buffered saline and incubated in $1 \mu \mathrm{g} / \mathrm{ml}$ DAPI (Sigma-Aldrich) (dissolved in methanol) for $5 \mathrm{~min}$ in the dark. Slides were mounted and observed using a Nikon ECLIPSE 80i fluorescence microscope (Nikon, Tokyo, Japan). Images were captured using a microscope-branched Nikon DS-Ri1 camera (Nikon).

DNA fragmentation assay. Cells were treated with $50 \mu \mathrm{M} \mathrm{ESC}$ for 12,16 and $24 \mathrm{~h}$ prior to harvesting. Genomic DNA was extracted using previously described methods (20). The DNA samples were separated using a 1.5\% agarose gel and DNA fragments were visualized by UV transillumination following ethidium bromdie staining. Fluorescence intensity was quantified using a Gel Doc 2000 system (Bio-Rad, Hercules, CA, USA) in order to determine the amount of DNA that was degraded upon treatment with $50 \mu \mathrm{M}$ ESC.

RNA extraction and reverse transcription-quantitative polymerase chain reaction ( $R T-q P C R)$ analysis. Cells were seeded at a density of $1 \times 10^{6}$ cells per $75 \mathrm{~cm}^{2}$ flask and cultured for $24 \mathrm{~h}$. The cells were treated with $50 \mu \mathrm{M}$ ESC for $6,18,24$ and $48 \mathrm{~h}$ prior to being harvested. Total RNA was extracted using a RNeasy kit (Qiagen, Valencia, CA, USA). The cDNA was directly prepared from total RNA using thr M-MLV RT First-Strand Synthesis System (Invitrogen Life Technologies, Carlsbad, CA, USA) and an oligo (dT) 12-18 primer (Invitrogen Life Technologies) according to the manufacturer's instructions. Transcript levels of caspase-8, caspase-3, caspase-9, p53, Bcl-2, Bax and a GAPDH reference gene were determined using transcript-specific primers (16). qPCR was performed with a StepOne/Plus Real-Time PCR system (Applied Biosystems, Foster City, CA, USA) according to the manufacturer's instructions for relative expression ( $\Delta \Delta \mathrm{Ct}$ method). Thus, the expression levels were expressed as relative fold differences compared with the expression levels of the reference gene.

Statistical analysis. The results were expressed as the mean value \pm the standard error of the mean of individual experiments. Comparisons of the means were conducted using a one-way analysis of variance followed by Bonferroni's post hoc test (Prism software, version 6.0 for windows; GraphPad Software, La Jolla, CA, USA).

\section{Results}

FT-IR spectroscopic analysis of L. papillosa extract. The simple yet efficient extraction method yielded considerable levels of SPs, which are originally found in appreciable levels in the red alga L. papillosa. Comparing the FT-IR spectrum of the ESC with the standard FT-IR spectra of the most common carrageenans ( $\kappa-, \mathrm{t}$ - and $\lambda$-carrageenans) revealed that the obtained ESC FT-IR spectrum is similar to the standard FT-IR spectrum of I-Carrageenan (Fig. 1) $(22,23)$. Notably, the spectrum obtained in the current study possessed two characteristic absorption bands at 847 and $802 \mathrm{~cm}^{-1}$ which are associated with $\mathrm{t}-$ carrageenan. The distinctive band at $802 \mathrm{~cm}^{-1}$ is associated with the sulfate group linked to the anhydrogalactose ring, whereas the clear $847 \mathrm{~cm}^{-1}$ band corresponds to the sulfated group bonded to the galactose ring. The broad band at $\sim 1250 \mathrm{~cm}^{-1}$ is readily assigned to the $\mathrm{S}=\mathrm{O}$ stretching vibration of sulfate groups $(24,25)$. Furthermore, the spectrum showed no marked peaks around 823 or $835 \mathrm{~cm}^{-1}$ which are usually observed in the other SPs, confirming the lack of other sulfate ester substitutions.

ESC inhibits the proliferation of MDA-MB-231 cells in a time- and concentration-dependent manner. Cells treated with series of increasing concentrations of ESC showed a reduction in cell viability in a time- and concentration-dependent manner (Fig. 2). Therefore, to elucidate the pathway that cells 


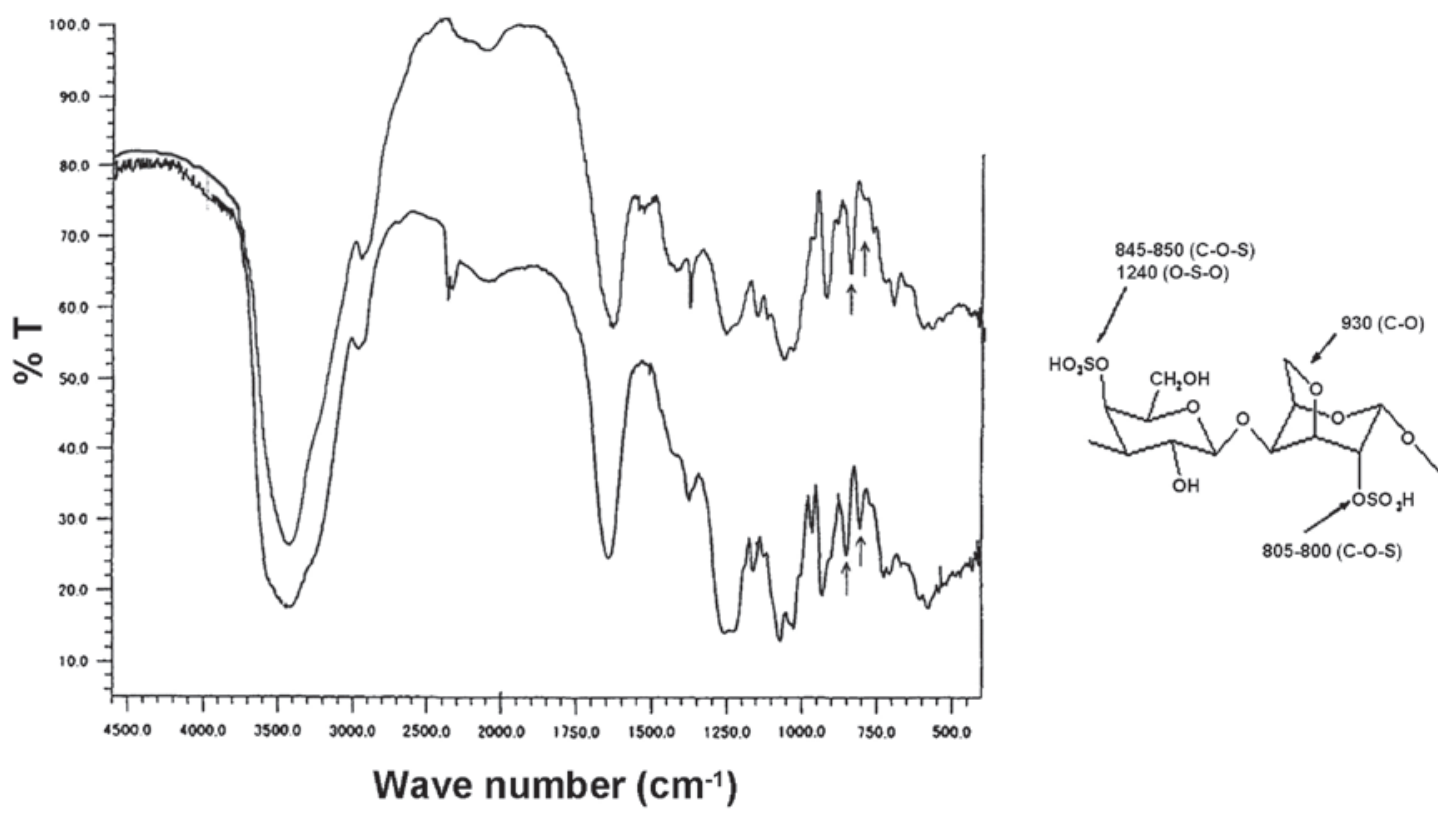

Figure 1. Molecular structure of t-carrageenan and its characteristic infrared (IR) bands $\left(\mathrm{cm}^{-1}\right)$. The Fourier transform (FT)-IR spectrum of the extracted polysaccharide in a potassium bromide (KBr) disc (upper line) and the t-Carrageenan reference-standard (lower line). The IR spectra were obtained using a Nicolet 6700 FT-IR spectrometer, with the samples dispersed in KBr disks. Arrows indicate the characteristic IR bands of iota-Carrageenan.

A

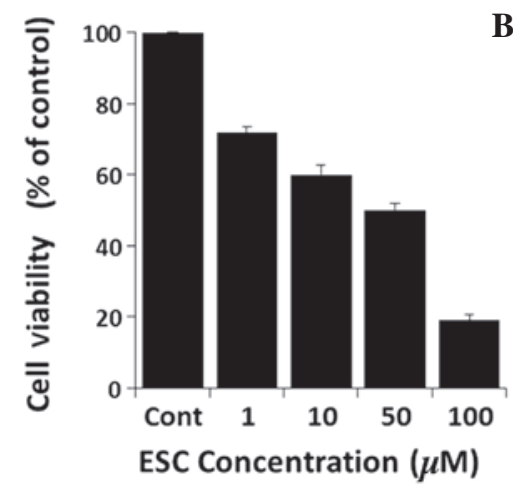

B

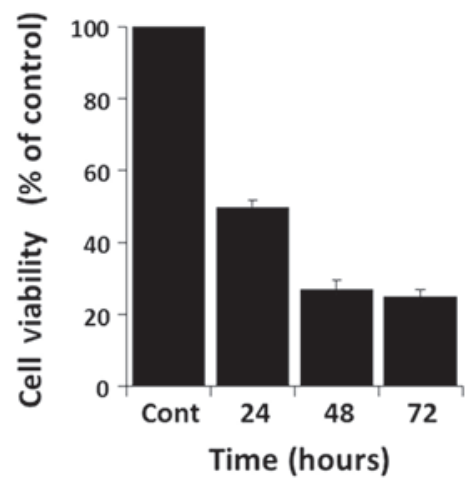

Figure 2. Extracted sulfated carrageenan (ESC)-induced cell injury and affected cell proliferation in a time- and concentration-dependent manner. (A) Cells were treated with five concentrations of $\operatorname{ESC}(1,10,50$ and $100 \mu \mathrm{M})$ over $24 \mathrm{~h}$. (B) Cells were treated with $50 \mu \mathrm{M}$ ESC for 24,48 and $72 \mathrm{~h}$. Cell viability was monitored using XTT assay. The percentage of cell viability was expressed as a ratio from the total viable cells of control (Cont), with each data point representing the mean \pm the standard error of the mean of three independent experiments.

were following when exposed to ESC, it was important to determine the half maximal inhibitory concentration $\left(\mathrm{IC}_{50}\right)$. ESC inhibited the proliferation of MDA-MB-231 cells in a concentration-dependent manner, with an $\mathrm{IC}_{50}$ value of $\sim 50 \mu \mathrm{M}$ (Fig. 2A). A time-course study at a concentration of $50 \mu \mathrm{M}$ revealed that ESC markedly reduced the cell viability in a time-dependent manner, as shown in Fig. 2B.

ESC induces morphological changes in MDA-MB-231 cells. To visually confirm the aforementioned biochemical results, bioimaging of ESC-treated cells was performed. Fig. 3A shows that cell proliferation was notably reduced by increasing concentrations of ESC. Control cells showed healthy growing patterns compared with those of the cells treated with $5 \mu \mathrm{M}$ of ESC, which had a rounded, shrunken appearance reflecting the classical signs of programmed cell death. The signs of biological injury in the compound-treated cells were clearer at higher concentrations
(20 and $50 \mu \mathrm{M})$. Higher concentrations of ESC led to a reduction in cell proliferation, evident by a greater number of shrunken rounded cells compared with those observed at lower concentrations. In addition, the morphological changes of ESC-treated cells were observed via DAPI staining. Apoptotic bodies, one of the morphological signs of apoptosis, were present in the $50 \mu \mathrm{M}$ ESC-treated cells stained with DAPI (Fig. 3B). Furthermore, nuclear condensation, which leads to the breakdown of nuclear DNA strands into multiple oligonucleosomal-sized fragments, was observed. ESC-treated cells showed an increase in the levels of DNA fragmentation following 12, 16 and $24 \mathrm{~h}$ of ESC treatment, confirming activation of apoptosis (Fig. 4A).

ESC alters apoptotic gene activity and caspase activation in MDA-MB-231 cells. The relative expression levels of genes involved in apoptosis were analyzed, including those of caspase-8, caspase-3, caspase-9, p53, Bcl-2 and Bax. 
A
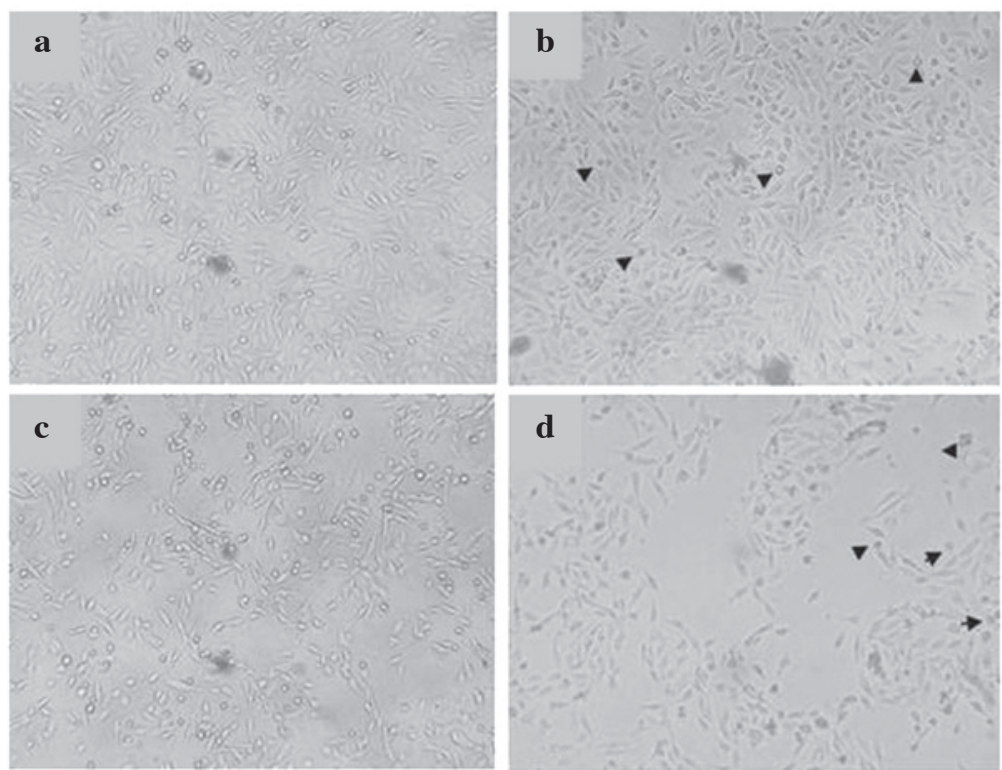

B
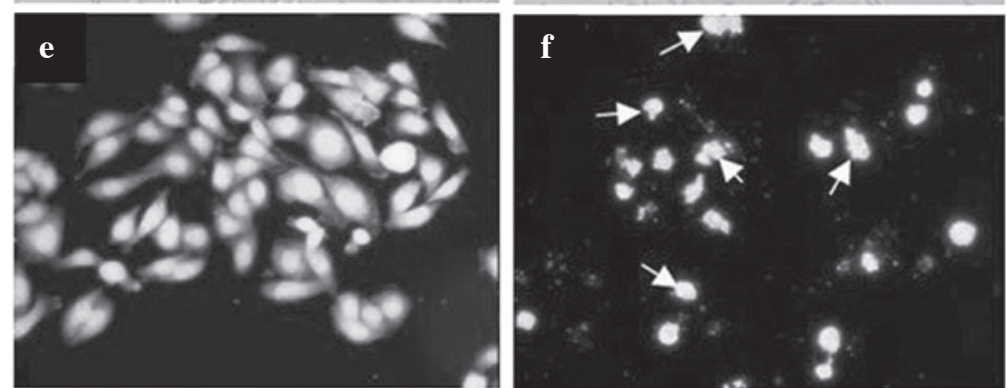

Figure 3. (A) Cell bioimaging investigation of ESC-treated cells. Cells were exposed to either (a) vehicle control DMSO or ESC (b) 5 (c) 10 or (d) $50 \mu \mathrm{M}$ for $48 \mathrm{~h}$. Following treatment, the formaldehyde-fixed cells were viewed under a microscope. Arrows show apoptotic cells as a result of ESC treatment. (B) The nuclear morphology and DNA condensation of the ESC-treated cells was evaluated using DAPI staining. Cells were exposed to either (e) vehicle control DMSO or (f) $50 \mu \mathrm{M} \mathrm{ESC} \mathrm{for} 24 \mathrm{~h}$. Cells were DAPI-stained and viewed under a fluorescence microscope. Arrows show nuclear condensation in apoptotic cells as a result of ESC treatment. (A-D, magnification, x100; E and F, magnification, $\mathrm{x} 400$ ).

A

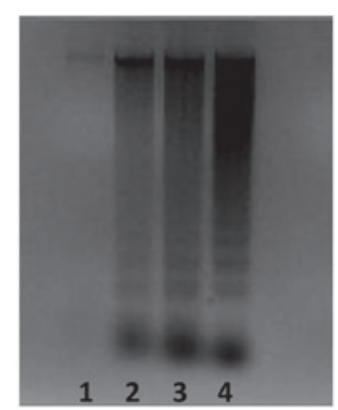

C

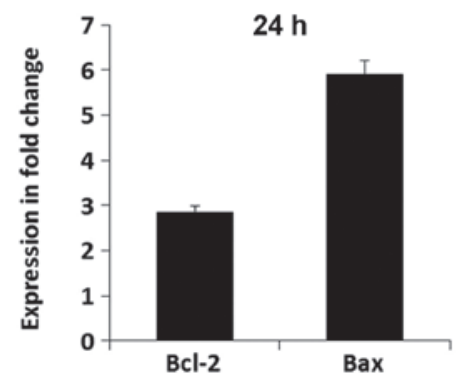

B

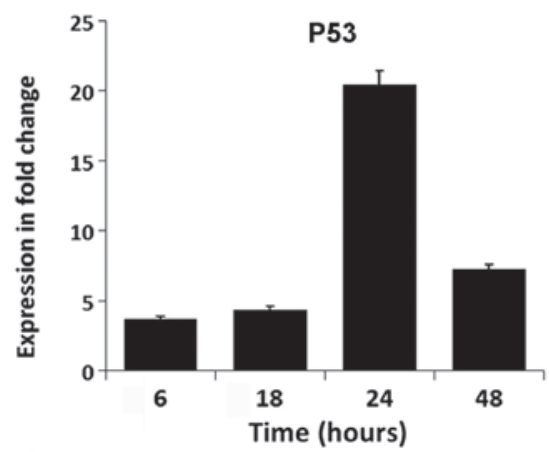

D

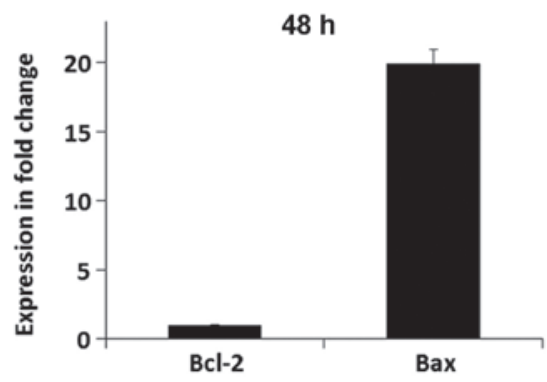

Figure 4. Induction of apoptosis via DNA fragmentation and regulation of p53, Bcl-2 and Bax. (A) DNA fragmentation assay: Cells were treated with $50 \mu \mathrm{M}$ extracted sulfated carrageenan (ESC) (lanes 2, 3 and 4) for 12, 16 or $24 \mathrm{~h}$, respectively. The non-treated control cells are in lane 1. (B) Comparison of p53 gene expression levels in cells as a relative fold change (ratio of target to reference gene) after 6, 18,24 and $48 \mathrm{~h}$ of exposure to $50 \mu \mathrm{M}$ of ESC. The ratio of Bax:Bcl-2 gene expression levels as a relative fold change in treated cells after (C) 24 and (D) $48 \mathrm{~h}$ of exposure to $50 \mu \mathrm{M}$ ESC. 
A

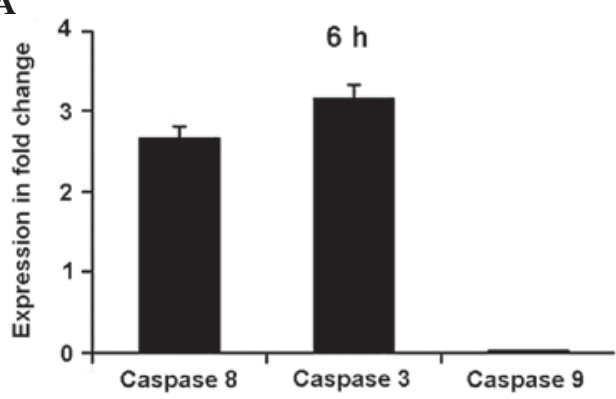

C

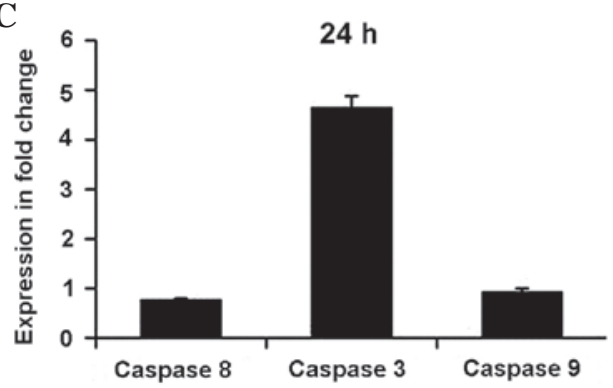

B

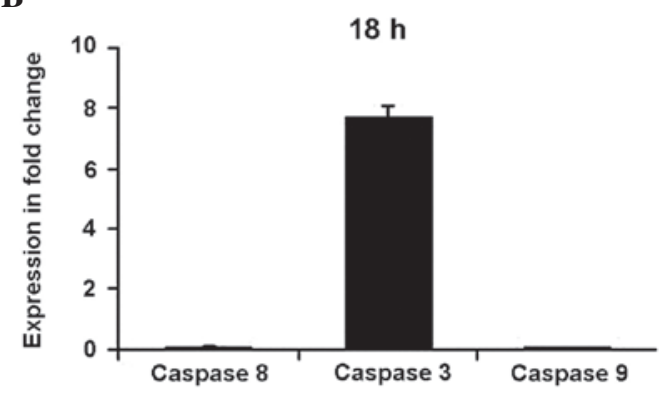

D

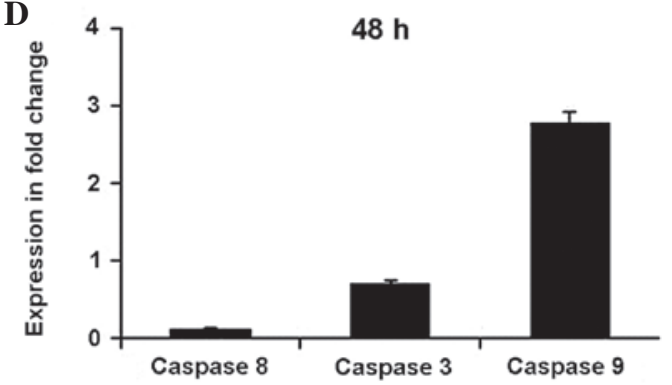

Figure 5. Expression of caspase genes after various periods of exposure to extracted sulfated carrageenan (ESC). Comparison of change in expression of caspase genes as a relative fold change (ratio of target to reference gene) in MDA-MB-231 cells after (A) 6, (B) 18 , (C) 24 and (D) 48 h of exposure to 50 $\mu \mathrm{M} \mathrm{ESC}$.

Figs. 4 and 5 summarize the gene expression changes. In the initial $6 \mathrm{~h}$, ESC increased the expression levels of caspase- 8 and caspase- 3 by several fold compared with those of the untreated cells (Fig. 5A). Subsequently, ESC maintained high levels (a several fold increase) of caspase-3 expression for 18 and $24 \mathrm{~h}$ as a result of the early expression of caspase-8, compared with those of the untreated cells (Fig. 5B and C). The expression levels of caspase- 9 only began to increase relative to the control cells after $24 \mathrm{~h}$, indicating the possibility of indirect activation by ESC. The expression levels were markedly increased by several fold after $48 \mathrm{~h}$ (Fig. 5D). In parallel, the expression levels of the oncogenic p53 gene were increased by 3.72-fold at $6 \mathrm{~h}$ and increased to 20.45-fold relative to the controls at $24 \mathrm{~h}$ (Fig. 4B). In the same time period, the apoptotic Bax:Bcl-2 expression ratio in $50 \mu \mathrm{M}$ ESC-treated cells was increased in a time-dependent manner. Comparably, the expression levels of Bcl-2 were reduced from2.85-fold at $24 \mathrm{~h}$ to 0.97 -fold at $48 \mathrm{~h}$. Conversely, Bax expression levels were significantly increased in ESC-treated cells to5.8-fold at $24 \mathrm{~h}$ and to 19.95 -fold at $48 \mathrm{~h}$ compared with those in the controls, indicating that the ESC-treatment induced apoptosis by increasing the Bax:Bcl-2 ratio (Fig. 4C and D).

\section{Discussion}

Marine alga metabolites have been recognized as a source of diverse and novel pharmacological molecules and compounds. Carrageenans, complex SPs, are considered to be major constituent compounds in a large group of edible red algae $(8,26)$. In the present study, FT-IR analysis revealed that the SPs extracted from L. papillosa have the characteristic spectra of l-carrageenan carbohydrate. The IR spectroscopic analysis of an algal extract from Eucheuma serra highlighted similar unique characteristics of t-carrageenan (23). In the last decade, several studies have indicated that a number of red algal SPs demonstrate anti-proliferative, pro-apoptotic, DNA-damaging, anti-angiogenic, growth-inhibiting, cell cycle-arresting and anti-metastatic functions $(27,28)$. Therefore, algal polysaccharides have become compounds of great interest due to their anti-cancerous activity (6,7). The anti-cancer mechanisms of SPs have been hypothesized to involve inhibition of the proliferation of tumor cells via the induction of apoptosis, which has been demonstrated in a number of tumor models, including those of melanoma, nasopharyngeal and gastric carcinomas and breast cancer $(11,29)$. The current study revealed that ESC exerts a cytotoxic inhibitory effect on MDA-MB-231 cells in a time- and concentration-dependent manner. Subsequently, the inhibition of the ESC-treated cells led to apoptosis. Similar studies have shown that the sulfated oligosaccharide PI-88 demonstrates effective anti-tumor activity in a pancreatic islet mouse melanoma via apoptosis (30). These results, along with the results of the present study, demonstrate that ESC has anti-proliferative properties that lead to apoptosis.

Induction of apoptosis via cytotoxic drug treatment has been shown to be a significant method of triggering cell death in a number of types of cancer (31). Therefore, an understanding of the events of apoptosis and its signaling pathway may allow for the development of novel agents for cancer treatment (32). Notably, the results of the current study demonstrated that ESC effectively induces the extrinsic pathway of apoptosis via regulation of the key molecule caspase- 8 in MDA-MB-231 cells. In addition, ESC-treated cells exhibit features that characterize apoptosis induced by the main executors caspase- 3 and caspase-9 (33), including nuclear condensation, DNA fragmentation and cell shrinkage (34-36). The Bax and Bcl-2 proteins are also known to regulate apoptosis promoted by different stimuli $(37,38) \cdot$ p53 is a direct transcriptional activator of the Bax gene (39), which interacts with $\mathrm{Bcl}-2$ to enhance outer 
mitochondrial membrane permeabilization. The increased expression levels of p53 induce an increase in the Bax:Bcl-2 ratio, resulting in the release of cytochrome $c$, the activation of caspase and ultimately apoptosis $(40,41)$. The biological activity of ESC algal extracts observed in the present study indicates a potential mechanism for the induction of cell apoptosis. These results concur with those of several previous studies on apoptosis induction via SP treatment $(27,28)$.

In conclusion, the results of the current study demonstrate that ESCs from the red alga L. papillosa inhibit cell growth and induce apoptosis in MDA-MB-231 cells via the recruitment of caspase-3, caspase- 8 and caspase-9, the re-modulation of the Bax:Bcl-2 ratio, and DNA damage. ESC may serve as a potential therapeutic agent and could be a promising target molecule in cancer prevention. Further studies are required to evaluate the potential anti-proliferative and anti-cancer activities of this extract in vivo.

\section{Acknowledgements}

This study was supported and funded by the Atomic Energy Commission of Syria (AECS). The authors thank the Director General of the AECS and the Head of the AECS Molecular Biology and Biotechnology Department for their support.

\section{References}

1. Pomin VH: Fucanomics and galactanomics: marine distribution, medicinal impact, conceptions, and challenges. Mar Drugs 10 793-811, 2012.

2. Cofrades S, López-López I, Bravo L, et al: Nutritional and antioxidant properties of different brown and red Spanish edible seaweeds. Food Sci Technol Int 16: 361-370, 2010.

3. Pujol CA, Scolaro LA, Ciancia M, Matulewicz MC, Cerezo AS and Damonte EB: Antiviral activity of a carrageenan from Gigartina skottsbergii against intraperitoneal murine herpes simplex virus infection. Planta Med 72: 121-125, 2006.

4. Magalhaes KD, Costa LS, Fidelis GP, et al: Anticoagulant, antioxidant and antitumor activities of heterofucans from the seaweed Dictyopteris delicatula. Int J Mol Sci 12: 3352-3365, 2011.

5. Fu BD, Bi WY,He CL, et al: Sulfated derivatives of 20(S)-ginsenoside $\mathrm{Rh} 2$ and their inhibitory effects on LPS-induced inflammatory cytokines and mediators. Fitoterapia 84: 303-307, 2013.

6. Chen LL, Chen X, Choi H, et al: Exploiting antitumor immunity to overcome relapse and improve remission duration. Cancer Immunol Immunother 61: 1113-1124, 2012.

7. Namvara F, Mohameda S, et al: Polyphenol-rich seaweed (Eucheuma cottonii) extract suppresses breast tumour via hormone modulation and apoptosis induction. Food Chem 130: 376-382, 2012.

8. Yang C, Chung D, et al: Effects of molecular weight and hydrolysis conditions on anticancer activity of fucoidans from sporophyll of Undaria pinnatifida. Int J Biol Macromol 43: 433-437, 2008.

9. Kamangar F, Dores GM and Anderson WF: Patterns of cancer incidence, mortality, and prevalence across five continents: defining priorities to reduce cancer disparities in different geographic regions of the world. J Clin Oncol 24: 2137-2150, 2006.

10. DeSantis C, Howlader N, Cronin KA and Jemal A: Breast cancer incidence rates in U.S. women are no longer declining. Cancer Epidemiol Biomarkers Prev 20: 733-739, 2011.

11. Yuan YV and Walsh NA: Antioxidant and antiproliferative activities of extracts from a variety of edible seaweeds. Food Chem Toxicol 44: 1144-1150, 2006.

12. Reddy BS, Cohen LA, McCoy GD, Hill P, Weisburger JH and Wynder EL: Nutrition and its relationship to cancer. Adv Cancer Res 32: 237-345, 1980.

13. Teas J: The consumption of seaweed as a protective factor in the etiology of breast cancer. Med Hypotheses 7: 601-613, 1981.

14. Hebert JR and Rosen A: Nutritional, socioeconomic, and reproductive factors in relation to female breast cancer mortality: findings from a cross-national study. Cancer Detect Prevent 20: 234-244, 1996.
15. Kodama M, Kodama T, Miura S and Yoshida M: Nutrition and breast cancer risk in Japan. Anticancer Res 11: 745-754, 1991.

16. Teas J, Vena S, Cone DL and Irhimeh M: The consumption of seaweed as a protective factor in the etiology of breast cancer: proof of principle. J Appl Phycol 25: 771-779, 2013.

17. Kim SK and Karagozlu MZ: Marine algae: natural product source for gastrointestinal cancer treatment. Adv Food Nutr Res 64: 225-233, 2011

18. Khanavi M, Nabavi M, Sadati N, et al: Cytotoxic activity of some marine brown algae against cancer cell lines. Biol Res 43: 31-37, 2010.

19. Patel S: Therapeutic importance of sulfated polysaccharides from seaweeds: updating the recent findings. 3 Biotech 2: 171-185, 2012.

20. Miller SA, Dykes DD and Polesky HF: A simple salting out procedure for extracting DNA from human nucleated cells. Nucleic Acids Res 16: 1215, 1988.

21. Lo YL and Liu Y: Reversing multidrug resistance in Caco-2 by silencing MDR1, MRP1, MRP2, and BCL-2/BCL-xL using liposomal antisense oligonucleotides. PLoS One 9: e90180, 2014.

22. Fenoradosoa TA, Delattre C, Laroche C, et al: Highly sulphated galactan from Halymenia durvillei (Halymeniales, Rhodophyta), a red seaweed of Madagascar marine coasts. Int J Biol Macromol 45: 140-145, 2009.

23. Lin LH, Tako $\mathrm{M}$ and Hongo $\mathrm{F}$ : Isolation and characterization of iota-carrageenan from Eucheuma serra (Togekirinsai). J Appl Glycosci 47: 303-310, 2000.

24. Chiovitti A, Bacic A, Craik DJ, Kraft GT and Liao ML: A nearly idealized 6'-O-methylated iota-carrageenan from the Australian red alga Claviclonium ovatum (Acrotylaceae, Gigartinales). Carbohydr Res 339: 1459-1466, 2004.

25. Liao ML, Chiovitti A, Munro SL, Craik DJ, Kraft GT and Bacic A: Sulfated galactans from Australian specimens of the red alga Phacelocarpus peperocarpos (Gigartinales, Rhodophyta). Carbohydr Res 296: 237-247, 1996.

26. Karnjanapratum S and You S: Molecular characteristics of sulfated polysaccharides from Monostroma nitidum and their in vitro anticancer and immunomodulatory activities. Int J Biol Macromol 48: 311-318, 2011

27. Xue M, Ge Y,Zhang J, et al: Anticancer properties and mechanisms of fucoidan on mouse breast cancer in vitro and in vivo. PLoS One 7: e43483 2012.

28. El Gamal AA: Biological importance of marine algae. Saudi Pharm J 18: 1-25, 2010 .

29. Wu Y, Tang W, Li CL, et al: Cytotoxicity of a newly synthesized nitroxide derivative of 4-ferrocenecarboxyl-2,2,6,6-tetramethylpiperidine-1-oxyl in high metastatic lung tumor cells. Pharmazie 61: 1028-1033, 2006.

30. Johnstone KD, Karoli T, Liu L, et al: Synthesis and biological evaluation of polysulfated oligosaccharide glycosides as inhibitors of angiogenesis and tumor growth. J Med Chem 53: 1686-1699, 2010.

31. Green DR and Kroemer G: The pathophysiology of mitochondrial cell death. Science 305: 626-629, 2004.

32. Hengartner MO: The biochemistry of apoptosis. Nature 407: 770-776, 2000.

33. Guessous I, Cornuz J and Paccaud F: Lung cancer screening: current situation and perspective. Swiss Med Wkly 137: 304-311, 2007.

34. Shah S, Gapor A and Sylvester PW: Role of caspase-8 activation in mediating vitamin E-induced apoptosis in murine mammary cancer cells. Nutr Cancer 45: 236-246, 2003.

35. Riedl SJ and Shi Y: Molecular mechanisms of caspase regulation during apoptosis. Nat Rev Mol Cell Biol 5: 897-907, 2004.

36. Cheah YH, Nordin FJ, Tee TT, Azimahtol HL, Abdullah NR and Ismail Z: Antiproliferative property and apoptotic effect of xanthorrhizol on MDA-MB-231 breast cancer cells. Anticancer Res 28: 3677-3689, 2008.

37. Gao Z, Shao Y and Jiang X: Essential roles of the Bcl-2 family of proteins in caspase-2-induced apoptosis. J Biol Chem 280: 38271-38275, 2005.

38. Cheah YH, Azimahtol HL and Abdullah NR: Xanthorrhizol exhibits antiproliferative activity on MCF-7 breast cancer cells via apoptosis induction. Anticancer Res 26: 4527-4534, 2006.

39. Miyashita T and Reed JC: Tumor suppressor p53 is a direct transcriptional activator of the human bax gene. Cell 80: 293-299, 1995.

40. Rassouli FB, Matin MM, Iranshahi $M$ and Bahrami AR: Investigating the cytotoxic and apoptosis inducing effects of monoterpenoid stylosin in vitro. Fitoterapia 82: 742-749, 2011.

41. Luo G, Guan X and Zhou L: Apoptotic effect of citrus fruit extract nobiletin on lung cancer cell line A549 in vitro and in vivo. Cancer Biol Ther 7: 966-973, 2008. 